\title{
Addressing a
} burning issue

\section{In this month's President's Column, Jenny Godson, President of the British Association for the Study of Community Dentistry (BASCD) gives us her views on the latest in dentistry.}

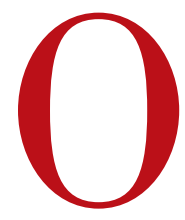

ne of the burning issues in dentistry and of course in general healthcare is the widespread consumption of free sugars especially in sugarsweetened beverages. This contributes not only to dental decay but also the increased risk of weight gain and obesity.

In July 2015, the Scientific Advisory Committee on Nutrition (SACN) published a comprehensive review of the scientific evidence concerning carbohydrates and health. They advised the government to halve the recommended intake of free sugars. The World Health Organisation (WHO) also recommended a reduction in free sugars intake.

\section{What is the issue?}

The latest National Diet and Nutrition Survey (2014) showed that in the UK we are consuming too much sugar with;

- $12 \%$ of adults' daily energy coming from sugar

- Teenagers (11 to 18 years) consuming three times the recommended sugar intake with the biggest source being sugary drinks

- $25 \%$ of the sugar in children's (4 to 10 years) diet coming from sugary drinks.

Sugar sweetened beverages have a direct effect on glycaemia and insulin resistance. A recent systematic review (Imamura et al, 2015) concluded that habitual consumption of sugar sweetened beverages is associated with a greater incidence of type 2 diabetes and that this appears to be independent of obesity.

The impact of dental caries and excess body weight and their disproportionate effect on those who are living in social deprivation are reasons why we should be concerned about excess intake of sugar. Despite being preventable, dental caries is the most common oral disease affecting children and young people in the UK, once it develops it is irreversible and the affected teeth may require long term maintenance following initial treatment. In addition dental decay in young children is a leading cause of childhood admission to hospital. A recent HSCIC report for the year 2013-14 highlighted that just under 26,000 five to nine year olds were admitted to hospital for the surgical removal of teeth due to tooth decay.

There is also a significant financial impact; in England the cost to the NHS for dental care is estimated to be $£ 3.4$ billion annually. In addition an estimated $£ 2.3$ billion is spent

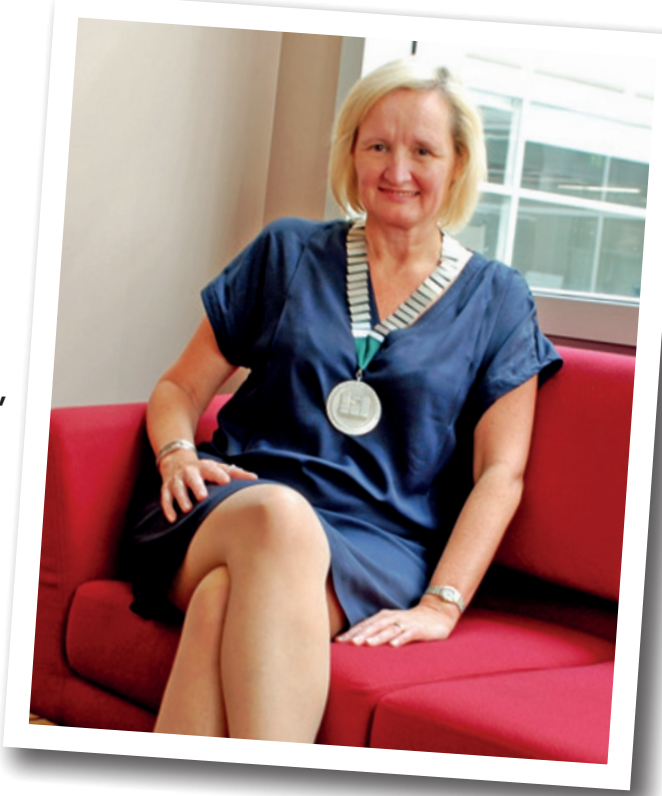

Health Forum will examine evidence from around the world on what actions work to reduce the intake of free sugars. Prof Richard Watt will consider the consumption of sugar sweetened beverages, the biggest source of sugars for children, and what actions work to reduce their consumption, including fiscal

\section{'DESPITE BEING PREVENTABLE, DENTAL CARIES IS THE MOST COMMON ORAL DISEASE AFFECTING}

\section{CHILDREN AND YOUNG PEOPLE IN THE UK'}

on private dental care. In Wales the net dental spend in 2013-14 was $£ 140.7$ million, plus $£ 30.3$ million in patient charges whilst in Scotland in 2013/14 the cost of NHS Dental Services was estimated at $£ 500$ million.

\section{Action to reduce the consumption} of free sugars

BASCD have decided to make free sugars central to our November scientific conference this year focusing on 'Action to reduce the consumption of free sugars- What is BASCD's view?' The BASCD autumn scientific meeting will be held on Thursday 19th November 2015 at Cavendish House in London. The one day meeting will develop a position statement to identify key evidence based actions that together will reduce the consumption of free sugars.

The morning session will include eminent speakers such as Prof Paula Moynihan, who authored the systematic review which informed the recent WHO guidelines and will be discussing what the halving of the consumption of free sugars will mean to everyday public health practice. Modi Mwatsama, Registered Nutritionist (public health) and Director - Global Health, UK measures such as a sugar tax. This should be a very interesting morning with plenty of chance for discussion and debate.

The afternoon session will take the form of workshops allowing members and delegates, having heard from our speakers, to contribute to the development of a BASCD position statement on action to reduce the consumption of free sugars. I would be delighted to welcome you to the conference.

\section{Rates are as follows (includes lunch and refreshments): \\ - Member £130 \\ - Non-member £150 \\ - Student/DCP£100 \\ For more information please call Jaki Walker on 01424316062 or 07830527409 or visit our website http://www.bascd.org}

bdjteam2015150 